\title{
Creep Failures in Laser Welded 316L(N) Stainless Steel Joints
}

\author{
D. Harish Kumar ${ }^{1}$, T. Sakthivel ${ }^{2}$, M. Nanda Gopal ${ }^{2}$, K. S. Chandravathi' ${ }^{2}$ K. Laha ${ }^{2}$, S. K. Albert ${ }^{2}$, \\ Hemanth Kumar' ${ }^{2}$ B. Shanmugarajan ${ }^{3} \&$ A. SomiReddy ${ }^{4}$ \\ ${ }^{1}$ Research Scholar, KITS, Warangal (A.P), India \\ ${ }^{2}$ Metallurgy and Materials Group, Indira Gandhi Center for Atomic Research, Kalpakkam (T.N), India \\ ${ }^{3}$ CLPM, ARCI Balapur, Hyderabad (A.P), India \\ ${ }^{4}$ Vivekananda Institute of Technology and Science Womens Engineering College, Karimnagar (A.P), India \\ Correspondence: D. Harish Kumar, Research Scholar, KITS, Warangal (A.P), India. Tel: 91-991-221-4678. \\ E-mail: badrakali4@gmail.com
}

Received: November 5, 2012 Accepted: November 22, 2012 Online Published: December 12, 2012

doi:10.5539/jmsr.v2n1p124 URL: http://dx.doi.org/10.5539/jmsr.v2n1p124

\begin{abstract}
Low carbon, nitrogen alloyed $316 \mathrm{~L}(\mathrm{~N})$ SS is an high temperature structural material for Fast Breeder Test Reactor (FBTR) applications. Laser welding is a non contact, low heat input widely accepted welding process for welding a wide variety of materials due to its advantages like deep narrow welds, minimum distortion, narrow heat-affected zone, excellent metallurgical quality, ability to weld smaller size, thinner and thicker components and increased travel speeds compared to other welding processes. Creep rupture tests have been carried out on laser welded $316 \mathrm{~L}(\mathrm{~N})$ SS joints at $650^{\circ} \mathrm{C}$. The Rupture behavior of these joints has been investigated at stresses in the range 180-220MPa. In the present paper an attempt has been made to present the results on the creep failure mechanisms of creep-ruptured laser welded $316 \mathrm{~L}(\mathrm{~N}) \mathrm{SS}$ joints. It has been observed that creep fracture occurred in an inter granular fashion at all the stresses that have been tested and creep cavitation was the dominant mechanism in controlling the creep rupture behavior.
\end{abstract}

Keywords: laser, welding, creep, cavities, voids

\section{Introduction}

The term creep indicates the permanent, time dependent deformation that occurs when a material is exposed to high temperature under a constant applied stress (or load). Creep is observed in all metals provided that the operating temperature $\mathrm{T}$ exceeds $0.3-0.5 \mathrm{~T}_{\mathrm{m}}$, where $\mathrm{T}_{\mathrm{m}}$ is the absolute melting temperature (Kaufman, 1999; Kassner, 2004; Arumulla, 1985). Creep deformation is monitored by measuring the creep strain at regular intervals of time and obtaining a plot of creep strain as a function of time. The plot so obtained is known as creep curve which depicts three stages: primary creep, secondary creep and tertiary creep. During the primary creep, the material gets work hardened and the creep rate decreases with time. During the secondary creep a balance exists between work hardening and softening and as a result of these, the creep rate remains constant. At the end of the secondary creep, the creep rate rapidly increases with time resulting in premature failure. This creep stage is known as tertiary creep. The secondary creep rate and the creep rupture time at the end of the tertiary stage are noted for design applications. The tertiary creep range is important because metallurgical damage such as voids and microcracking begins to occur. The onset of tertiary creep is a sign that structural damage is occurring and the component is nearing an end to its design life even though the actual time to rupture can be long (Kaufman, 1999).

Creep failures have been ascribed traditionally to grain boundary cavitation and wedge crack formation at the triple boundary junctions (Arumulla, 1985). Voids nucleate along the grain boundaries, link up together to form micro- cracks. Grain boundary sliding is a prerequisite for the nucleation of cavities along the grain boundaries and wedge cracks at the triple boundary junctions. For wedge cracks to nucleate at triple point regions, it is usually necessary to have stress concentrations of sufficient magnitude developed due to boundary sliding. In addition, these stress concentrations at triple point regions must not be relaxed by intense plastic flow within the grains. The progress of creep deformation is usually revealed by the appearance of slip lines within the grains and the slip line density increases with time. Slip bands may also form with in the grains and once deformation 
concentration occurs within these bands, failure may occur due to nucleation of cavities and cracks within these bands (Arumulla, 1985).

The effects of welding processes like Shielded Metal Arc Welding (SMAW), Multi-Pass Tungsten Inert Gas Welding (MP-TIG), Submerged Arc Welding (SAW) (Woo Gon Kim et al., 2007) and Activated flux Tungsten Inert Gas Welding (A-TIG ) (Vasudevan et al., 2007; Chandrasekhar et al., 2010; Vasantharaja et al., 2012; Vasudevan et al., 2009) on the mechanical properties of different grades of austenitic stainless steels have been investigated in detail by numerous workers in the past. However the effects of other welding processes like Electron Beam Welding (EBW), Activated flux Electron Beam welding (A-EBW) and Laser Beam Welding (LBW) (Harish Kumar et al., 2009) on the mechanical properties of atleast 316L(N) stainless steel have not been studied in detail. In the present investigation constant load creep tests have been carried out on laser welded $316 \mathrm{~L}(\mathrm{~N})$ stainless steel joints and $316 \mathrm{~L}(\mathrm{~N}) \mathrm{SS}$ base material. The $316 \mathrm{~L}(\mathrm{~N})$ base material is used as a high temperature structural material for FBTR applications (Reddy et al., 1980; Girish Shastry et al., 2004; Harish Kumar et al., 2010; Baldev Raj et al., 2010; Ganesan et al., 2010; Sakthivel et al., 2011; Mishra et al., 1997; Mathew et al., 2012; Tjong et al., 1995). The selection of this material is based on the considerations of its compatibility with liquid sodium coolant, superior creep strength at the FBTR operating temperatures, weldability availability of design data, resistance to oxidation and resistance to corrosion and free from sensitization (Girish Shastry et al., 2004; Sakthivel et al., 2011; Tjong et al., 1995; Sakthivel et al., 201). The $316 \mathrm{~L}(\mathrm{~N})$ stainless steel contains chromium, nickel, and molybdenum as major alloying elements. It also contains carbon in the range $0.02-0.03 \mathrm{wt} \%$ and nitrogen in the range $0.07-0.21 \mathrm{wt} \%$. The strength properties of $316 \mathrm{~L}(\mathrm{~N})$ SS decreases due to reduced carbon content (Ganeshan et al., 2012). The decrease in the strength properties of this steel due to reduced carbon content will be compensated by the solid solution strengthening of nitrogen. (Baldev Raj et al., 2010). The strength properties of this steel usually vary in the range 580-800 MPa which depends on the nitrogen content (Ganesan et al., 2010; Harish Kumar et al., 2010; Sakthivel et al., 2011; Mishra et al., 1997; Mathew et al., 2012). To study the creep- rupture behavior of the $316 \mathrm{~L}(\mathrm{~N}) \mathrm{SS}$, three stresses have been selected which varied in the range 0.3-0.4 UTS. Optical microscope has been used to delineate the weld bead appearance. Studies have also been carried out on the creep ruptured samples using optical microscope to know the mechanisms of creep fracture. Scanning Electron Microscope (SEM) has also been used to know the type of fracture.

\section{Experimental Details}

The chemical composition of the type $316 \mathrm{~L}(\mathrm{~N}) \mathrm{SS}$ used for the fabrication of weldments is given in Table 1 .

Table 1. Chemical composition (wt.\%) of type 316L(N)SS and deposited weld metals

\begin{tabular}{ccc}
\hline Material & 316L(N)SS Base plate & 316L(N)SS Weld Metal \\
\hline $\mathrm{C}$ & 0.028 & 0.025 \\
$\mathrm{Cr}$ & 17.5 & 17.6 \\
$\mathrm{Ni}$ & 12.2 & 12.2 \\
$\mathrm{Mo}$ & 2.3 & 2.41 \\
$\mathrm{Mn}$ & 1.65 & 1.7 \\
$\mathrm{Si}$ & 0.44 & 0.36 \\
$\mathrm{~N}$ & 0.085 & 0.082 \\
$\mathrm{~S}$ & 0.01 & 0.006 \\
$\mathrm{P}$ & 0.024 & 0.021 \\
$\mathrm{Fe}$ & Balance & Balance \\
Ferrite Number, FN & 0.13 & $0.08,(3.5 \mathrm{KW}) 0.083(3 \mathrm{KW})$ \\
\hline
\end{tabular}

Plates of $300 \mathrm{~mm}$ length $\times 125 \mathrm{~mm}$ width $\times 5.5 \mathrm{~mm}$ thickness were butt welded using $\mathrm{CO}_{2}$ laser. Prior to welding, the plates were thoroughly degreased, flat machined the edges and ensured negligible gap between the plates when the two abutting plates were tight fitted using clamps. Nitrogen shielding gas was used during welding of $316 \mathrm{~L}(\mathrm{~N}) \mathrm{SS}$ plates in the fabrication of two weldments one with $3.0 \mathrm{KW}$ laser power and the other one with 3.50 $\mathrm{KW}$ laser power. Using Argon as a shielding gas one more weldment has been fabricated using $3.0 \mathrm{KW}$ laser 
power in order to know the effects of shielding gas on the soundness of weld deposits. The shielding gas flow rate has been maintained at 30 liters per minute in the fabrication of weldments. A constant welding speed of 1 $\mathrm{m} /$ minute was used. All the weldments have been subjected to the X-Ray radiographic examination for their soundness. The chemical composition of the deposited welds is also given in Table 1. Transverse tensile test samples were machined for carrying out the tension tests at room temperature and at $650^{\circ} \mathrm{C}$. The sample design used for testing the samples in tension is given in Figure 1.

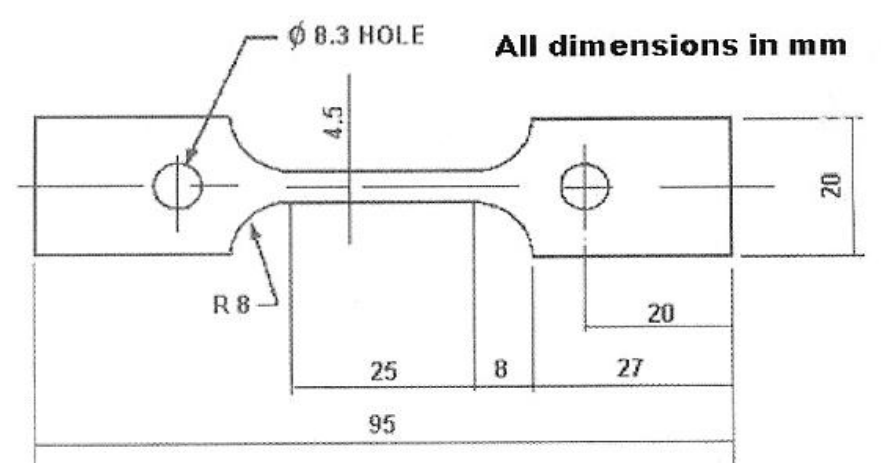

Figure 1. Tension test sample design

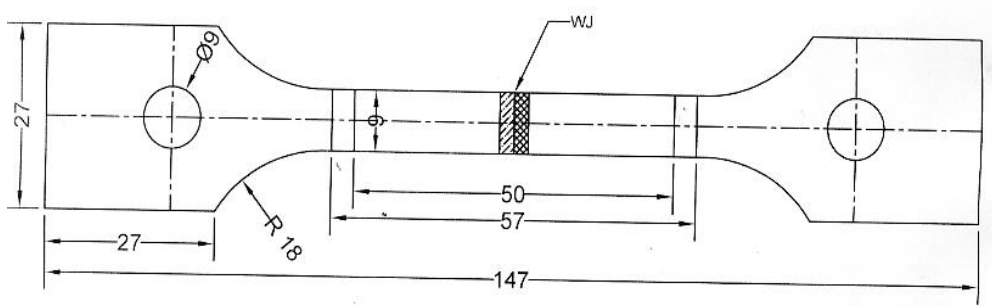

Figure 2. Creep Test Sample design

Figure 2 gives the sample design for carrying out the creep rupture tests. Constant load creep tests in air were carried out on the base metal and weld joints at 923K over a stress range of 180-220 MPa. Single creep test was carried out at each material in air under the prescribed test condition, and was repeated whenever found necessary. Temperature was controlled to within $\pm 2 \mathrm{~K}$ along the gauge length of the specimen during the creep test. Elongation of the creep specimens was monitored by an extensometer and digital dial gauge attachment having measuring accuracy of $\pm 0.001 \mathrm{~mm}$ and was logged in a data logger. Metallographic samples were machined from the weldments. The machined metallographic samples were subjected to usual emery polishing followed by cloth polishing procedures, ultrasonically cleaned, etched in an electrolytic bath containing $60 \%$ $\mathrm{HNO}_{3}$ and $40 \%$ water for 15 seconds at 3 volts to reveal weld fusion zone micro structures, heat affected zone and base metal microstructures. Immersion etching in boiling Murakkami's etchant (10g potassium ferric cyanide, $10 \mathrm{~g}$ potassium hydroxide and $100 \mathrm{ml}$ water) was used to reveal the delta ferrite. Ferrite scope was also used to know the ferrite numbers in the base metal and fusion zone. The ferrite scope had a measuring accuracy of $0.01 \%$. Micro-Hardness tests were also carried out across the weldments. The micro hardness tester having measuring accuracy of $1 \%$. Optical Microscope was used to reveal the microstructures of the fusion zone, heat effected zone and the base metal. Scanning electron microscope was used to know the type fracture and the extent of cavitation damage on the creep ruptured samples was observed under an optical microscope.

\section{Results and Discussion}

\subsection{Mechanical Properties}

In laser welding the gap between the two plates to be butt welded is one of the most important issues to be solved because the gap results in the formation of various weld defects such as under filling or non bonded joint, lack of fusion, porosity, under cuts (Codigo et al., 2009). The gap tolerance in butt joints is dependent on the 
material thickness, welding speed, beam diameter, and beam quality. It may be noted that the gap tolerance increases with material thickness. However as the gap increases, their reinforcement normally associated with line-on-line fit up of laser welds decreases. In the present study, zero gap has been maintained prior to laser welding and noted the importance of gap tolerances in controlling the weld metal quality during welding. The effects of zero gap on the weld metal quality have been reported variously in the literature Wouters et al. (2006) reported that maintaining a zero gap prior to welding gives a weak weld. This effect they have attributed to the weld geometry within which they have observed a sharp crack where the unweld parts met each other. Codigo Do Trabalho has studied systematically the effects of the gap tolerances on the weld metal quality of 316 SS $\mathrm{Nd}$ :YAG pulsed laser welded joints by varying the gap in the range 0-350 microns. Pores were observed in specimens with zero gap. Presence of spatter was observed in wider gaps. In the present study, no pores and no cracks were observed with zero gap. However the weldment which fabricated with the argon as the shielding gas revealed the presence of undercuts, lack of fusion and spatter with zero gap. In view of its poor weld metal quality, the $3.0 \mathrm{KW}$ laser power and argon shielded, laser fabricated weldment of $316 \mathrm{~L}(\mathrm{~N})$ has not taken up further for carrying out microstructure and mechanical property studies.

The results of the tension tests conducted on the transverse samples machined from the $3.0 \mathrm{KW}$ and $3.50 \mathrm{KW}$ laser welded joints are given in Table 2, along with the base metal.

On comparison, it could be seen that the properties of the welded joints are not significantly different from those of the base metal. The yield strength, $0.2 \%$ proof stress and ultimate tensile strength properties of the welded joints fabricated at $3.0 \mathrm{KW}$ and $3.50 \mathrm{KW}$ laser power are more or less remain unchanged from the base metal.

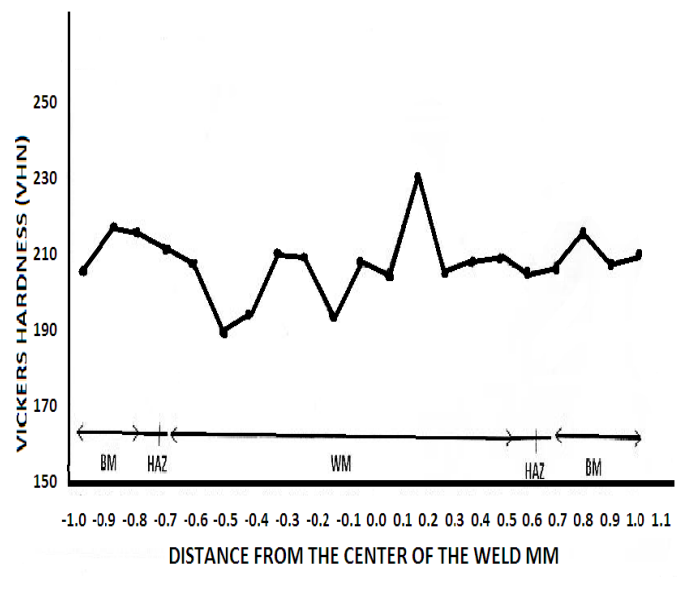

(a)

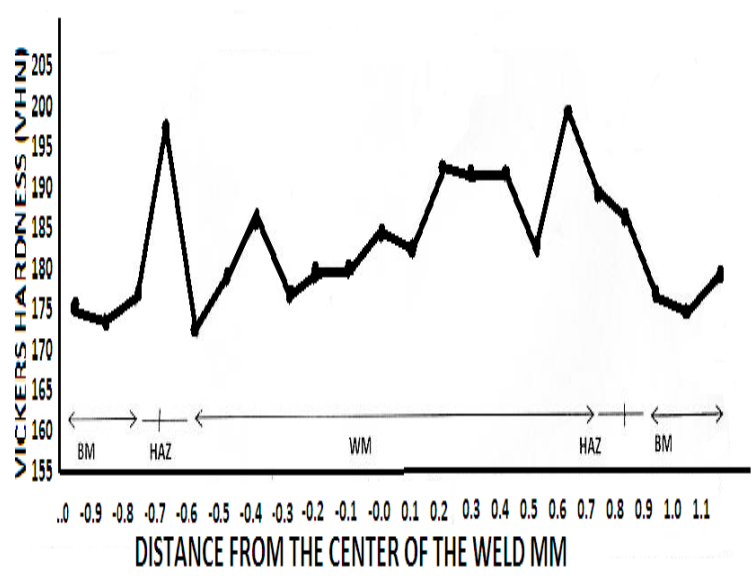

(b)

Figure 3. (a) Variation of Micro Hardness across the 3.0KW Laser Welded 316L(N) Joints; (b) Variation of Micro Hardness across the 3.5KW Laser Welded 316L(N) Joints

Micro- hardness test results shown in Figure 3(a) and 3(b) are also well in agreement with the above observations. The fusion zone in the case of 3.0KW laser welded 316L(N)SS recorded an average value of 206.2 VHN as compared to base metal value of $212.16 \mathrm{VHN}$. Whereas, the fusion zone in the case of $3.5 \mathrm{KW}$ laser welded $316 \mathrm{~L}(\mathrm{~N}) \mathrm{SS}$ has shown an average micro hardness value of $184 \mathrm{VHN}$ as compared to the base metal which showed an average value of $176 \mathrm{VHN}$. This is around $4.5 \%$ improvement on the strength properties of the fusion zone. The Heat Affected Zone [HAZ] showed an average value of 192 VHN which is $12.5 \%$ improvement on the strength properties of the weld deposits. The higher hardness recorded in the HAZ could be due to insitu cooling and formation of dendritic structures growing from the basemetal. The variation in the micro hardness values of fusion zone could be due to the differences in the fusion zone microstructures. In the fusion zone equiaxed and columnar structures were observed. Saktivel et al. (2011) have reported that equiaxed structures are softer than the columnar. However, some differences have been observed on the ductility properties of the welded joints as revealed by percentage elongation. The $3.0 \mathrm{KW}$ laser welded joints had shown higher ductility as compared to $3.50 \mathrm{KW}$ laser welded joints. However, the room temperature fracture of both the tension tested samples when observed under SEM revealed failure in transgranular fashion with familiar ductile dimples due to void coalescence on the fracture surface (Figure $4 \mathrm{a}$ and Figure $4 \mathrm{~b}$ ). 


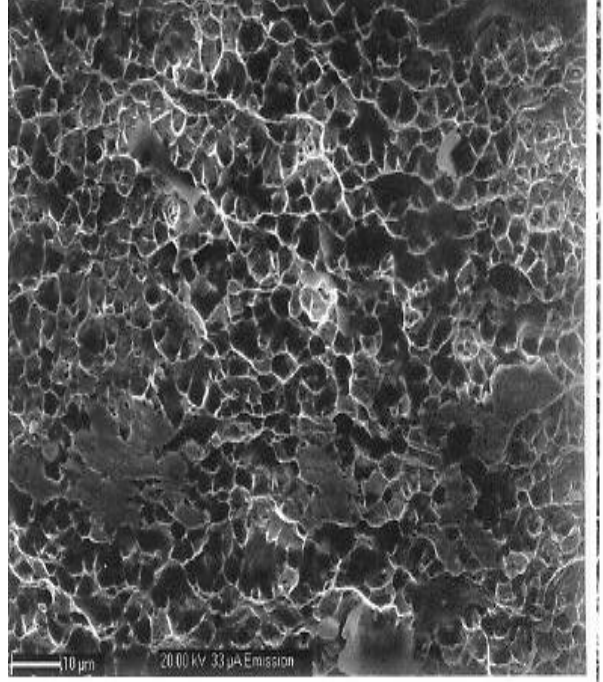

(a)

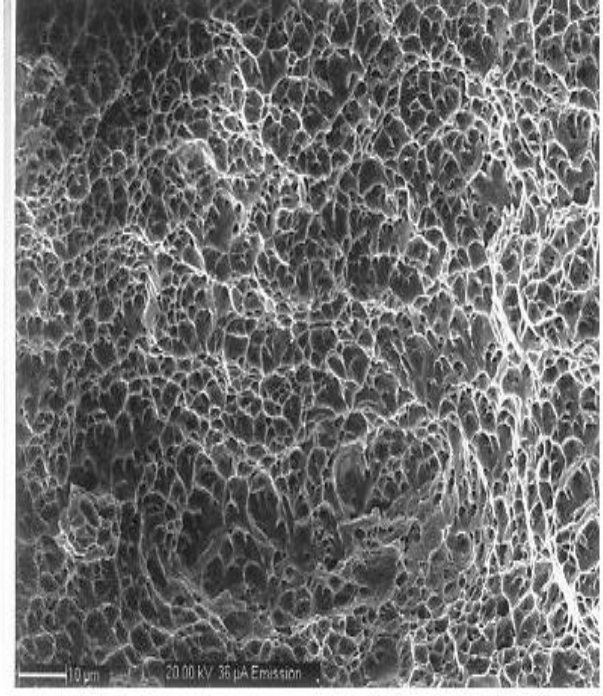

(b)

Figure 4. Transgranual Fracture of the Laser Welded (a) 3.0KW and (b) $3.5 \mathrm{KW}$ laser power

Except in one case, the failures of $650^{\circ} \mathrm{C}$ tension tested samples of both the weldments occurred in an intergranular fashion. In the other sample tested condition mixed mode of failure was observed. Whereas, the percentage reduction in area of both the welded joints remain unaltered from that of the base metal.

The charpy impact test results of the base metal are compared with those of the welded joints fabricated at 3.0 KW and 3.50 KW laser power in Table 2. It may be noted that the impact strength properties of the both the welded joints had shown same values to those of the base metal.

The creep rupture properties of laser welded $316 \mathrm{~L}(\mathrm{~N}) \mathrm{SS}$ are given in Table 3 where rupture lives of weld deposits are compared with those of basemetal it may be noted that the $3.0 \mathrm{KW}$ laser power and 180 Mpa rupture samples showed weak strength under creep at $650^{\circ} \mathrm{C}$. At other stresses, the weld deposits displayed superior strength then the basemetal. Others (Tjong et al., 1995) have reported that the $2.6 \mathrm{KW}$ welded joints were weaker than the basemetal. Upon comparing laser welded joints with the electron beam welded joints, Tjong et al., have observed that both have almost similar creep ruptured properties.

\subsection{Microstructures}

In the as welded condition, the fusion zone has not revealed any delta ferrite when immersion boiling Murakkami's etchant was used and observed under optical microscope. The weldments were then subjected to ferrite scope for the measurement of delta ferrite across the welded joints. The ferrite scope results given as Ferrite numbers (FN) in Table 1 reveal that the weld deposit FNs are considered to be insignificant as compared to those of the other welding processes. Figure 5(a) gives the weld bead appearance of the laser welded 316L(N) SS with $3.5 \mathrm{KW}$ laser power. Single pass with the solidified weld zone between the two abutting base plates is clear. It appears that the solidification initiated at the base metal, progressed epitaxially and got terminated after meeting the growing solid/ liquid interface from the other side of the weld bead. There is an equiaxed microstructure formed by heterogeneous nucleation due to dendritic fragmentation. The fusion zone microstructure as shown in Figure 5(b) shows equiaxied and dendritic structures. 


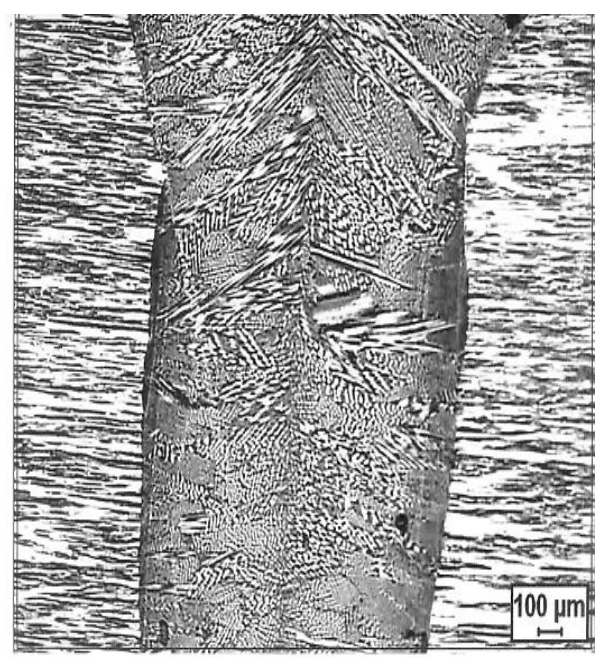

(a)

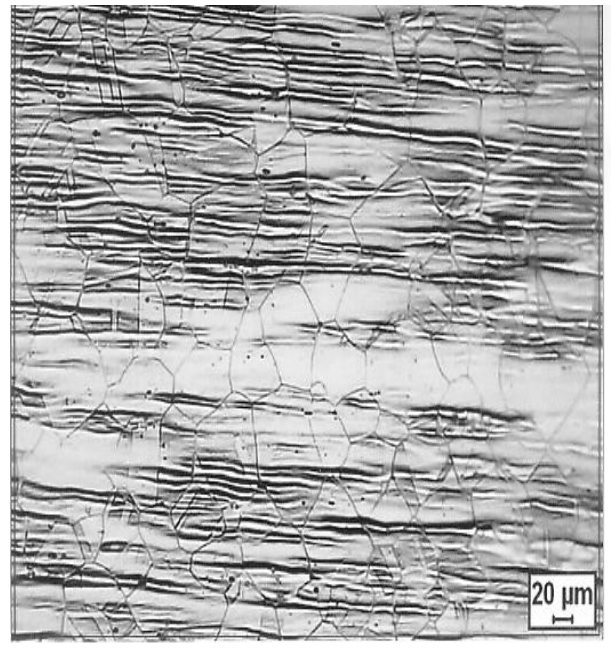

(c)

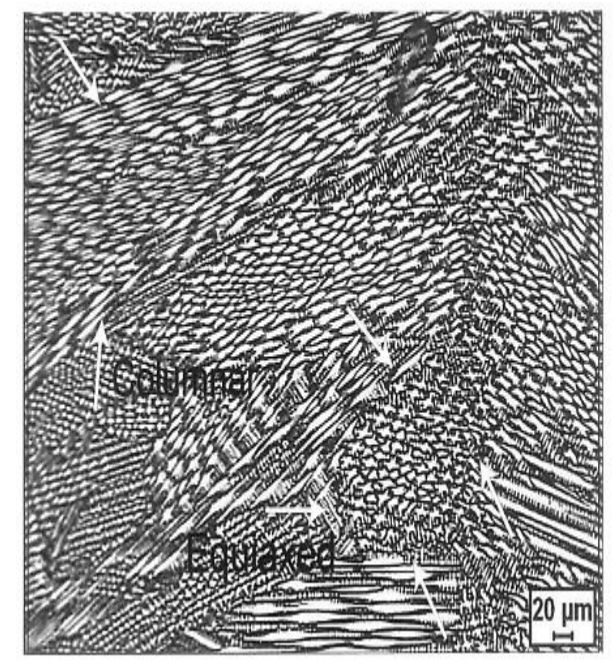

(b)

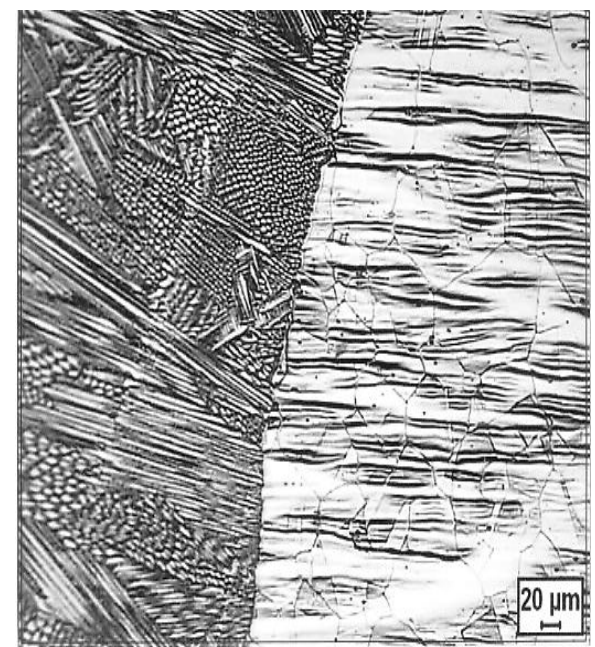

(d)

Figure 5. (a) Weld bead appearance of 3.5KW laser welded 316L(N) SS; (b) Fusion zone microstructure showing equiaxed and columnar microstructures; (c) 316 L(N) SS Base metal showing re-crystallized austenitic grain structure; (d) Base metal weld metal interface showing epitaxial microstructure

The mechanisms and conditions for the formation of dendritic and equiaxed grains in the weld metal have been discussed systematically by Saktivel et al. (1980). The epitaxial and competitive growth of solidified weld metal from the basemetal leads to the formation of dedritic structure in the weld metal when the heat input relatively low and cooling rate is relatively high Figure 5(b). The formation of equiaxed grain in weld pool will be favored under the conditions of high heat input and low cooling rate leading to dendrite fragmentation and grain detachment and hetero generous nucleation. Figure 5(c) shows re-crystallized austenitic grains of the cold worked basemetal with the average austenitic grain size of $75 \mu$. The fusion zone basemetal interface micro structure shown in Figure 5(d) reveal the epitaxial microstructure originating from the base metal.

The near fracture regions of the creep ruptured laser welded $316 \mathrm{~L}(\mathrm{~N}) \mathrm{SS}$ samples at stresses in the range $180-$ $220 \mathrm{MPa}$ have been studied under optical microscope to know the mechanisms of creep failures. 


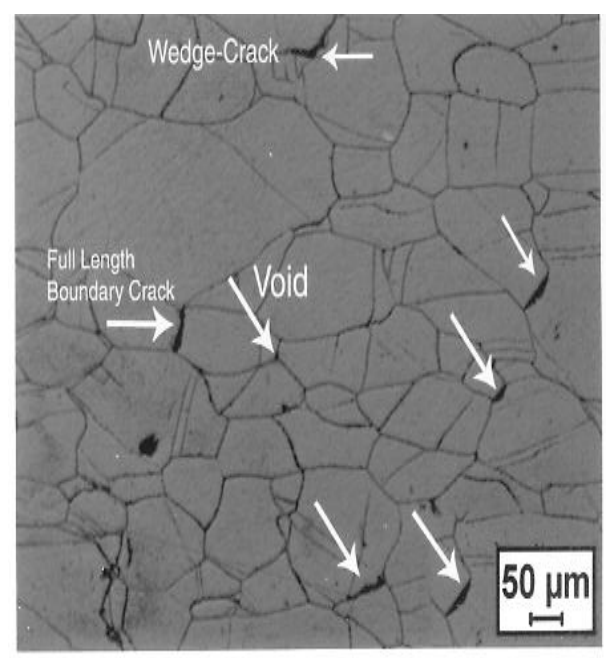

(a)

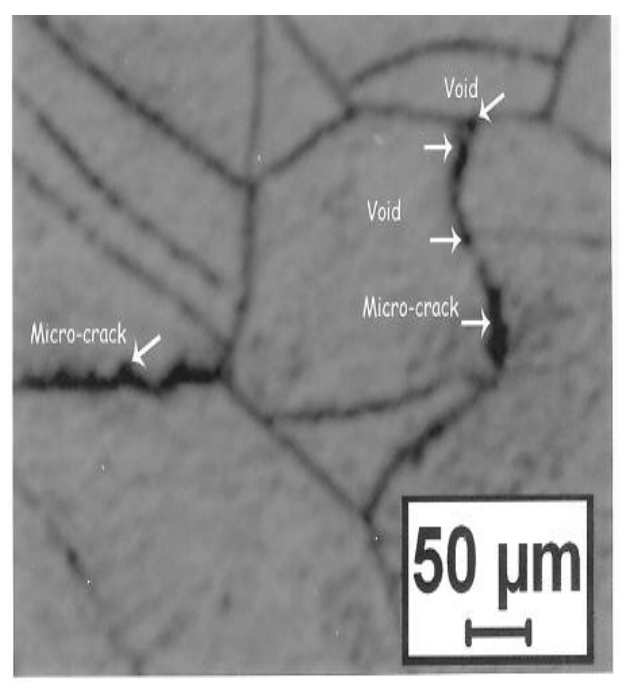

(c)

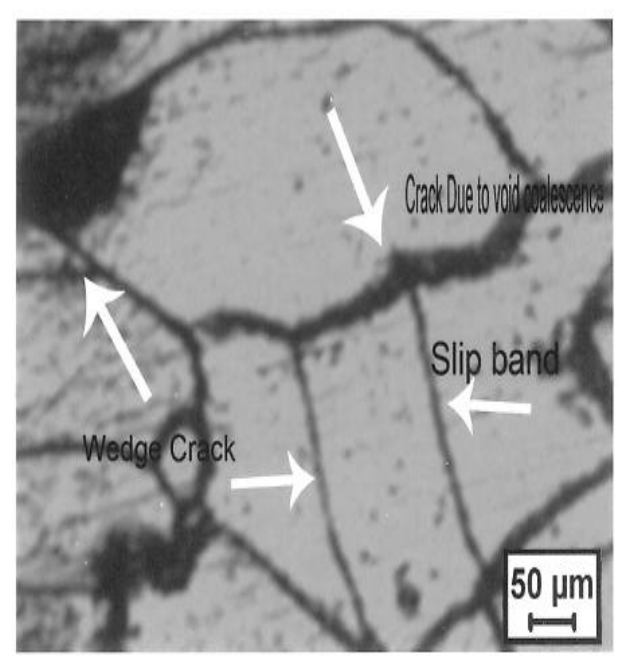

(b)

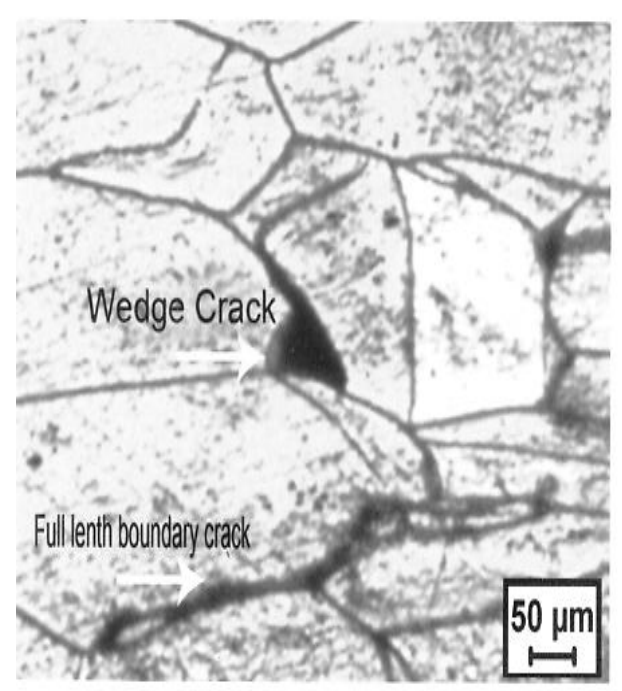

(d)

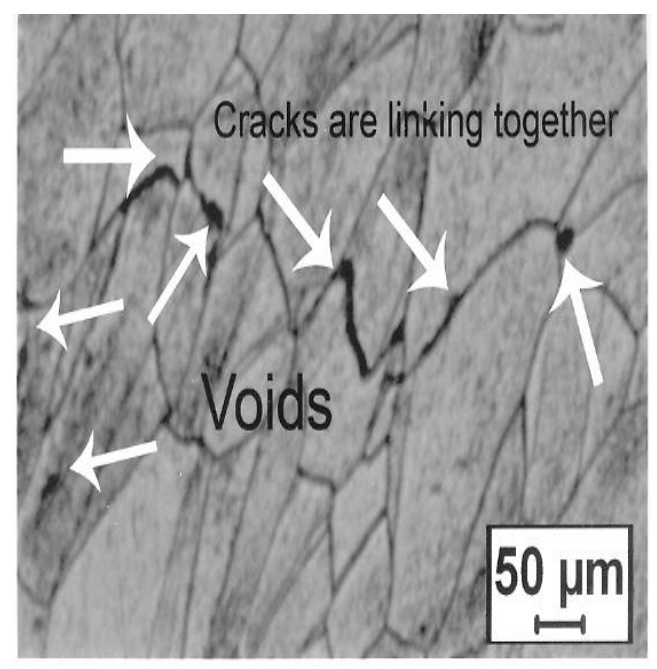

(e)

Figure 6. 
Figure 6(a) shows the extent of creep damage in the near fracture region of the $3.5 \mathrm{KW}$ laser welded $200 \mathrm{MPa}$ stress creep tested $316 \mathrm{~L}(\mathrm{~N})$ SS. The damage could be seen in the form of voids, micro cracks and wedge cracks. The extent of damage at $220 \mathrm{MPa}$ stress on the near fracture region of the laser welded $316 \mathrm{~L}(\mathrm{~N}) \mathrm{SS}$ is given in Figure 6(b).

Figure 6(b) shows damage in the form of wedge cracks and full length boundary cracks formed due to void coalescence. At the regions where the slip bands intersected the grainboundary nucleation of voids were also observed.

Figure 6(c) shows voids, micro cracks and the formation of micro cracks due to void coalescence in the $3.5 \mathrm{KW}$, laser welded $200 \mathrm{MPa}$ creep tested 316L(N)SS; (d) shows wedge cracks at triple boundary junctions and full length boundary crack due to linkage of micro cracks.

Figure 6(e) shows voids along the grain boundaries and the formation of major crack due to the linkage of full length boundary cracks in the $3.5 \mathrm{KW}$ laser welded and $180 \mathrm{MPa}$ creep tested $316 \mathrm{~L}(\mathrm{~N}) \mathrm{SS}$. Overall, it could be seen that at 200 and $220 \mathrm{MPa}$ stress wedge crack population at the triple boundary junctions was higher. At 180 MPa stress cavities nucleated along the grain boundaries, at triple boundary junctions and at the regions where slip bands intersected the grain boundary. The results are well in agreement with the others who reported that wedge cracks nucleate at higher stresses. The observation on the near fracture regions of the creep tested samples in the stress range 180-220 MPa also inagreement with the SEM fracture surfaces where interconnected cavities leading to intergranular fracture could be evident Figures 7(a) and 7(b).

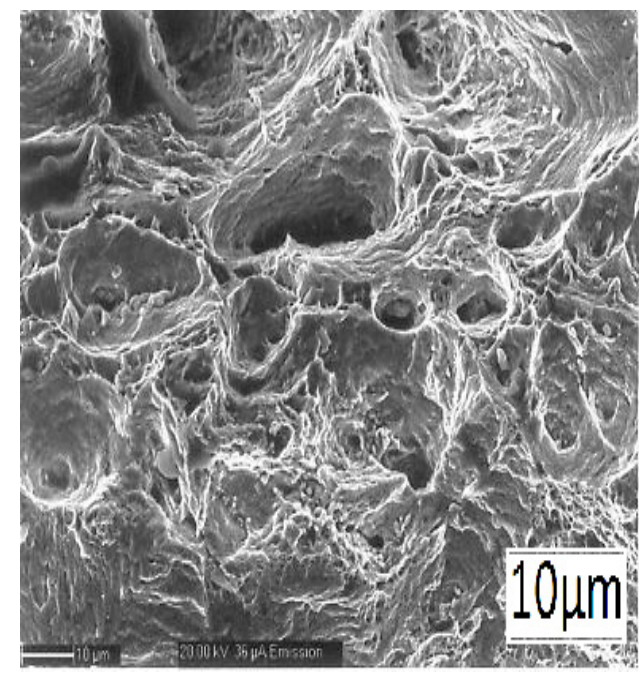

(a)

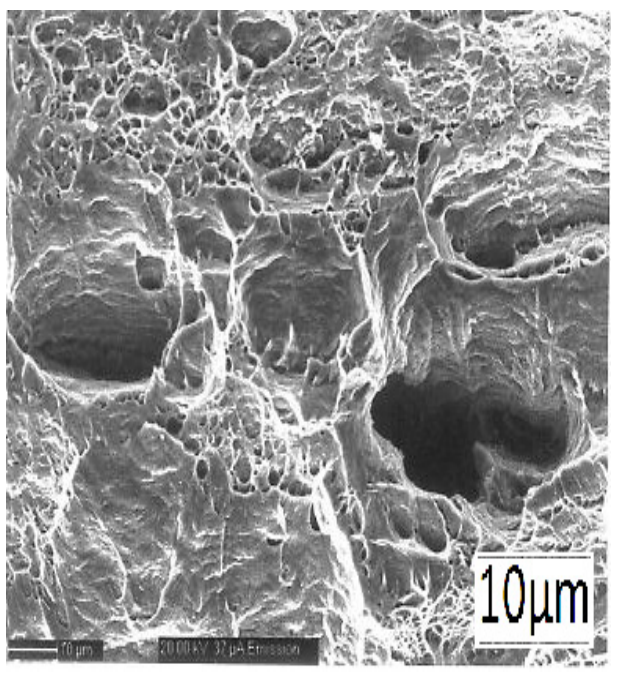

(b)

Figure 7. (a) Fracture surface of the $3.5 \mathrm{KW}$ laser welded creep tested at $180 \mathrm{MPa}$; (b) Fracture surface of the $3.5 \mathrm{KW}$ laser welded creep tested at $220 \mathrm{MPa}$

Table 2. Room Temperature and High Temperature Tensile Properties of 316L (N)SS Welded Joints

\begin{tabular}{|c|c|c|c|c|c|c|c|c|c|c|c|c|}
\hline \multirow{3}{*}{$\begin{array}{l}\text { Sl } \\
\text { No. }\end{array}$} & \multirow{3}{*}{$\begin{array}{l}\text { Power, } \\
\text { KW }\end{array}$} & \multicolumn{9}{|c|}{ Tensile Properties } & \multicolumn{2}{|c|}{ Impact Properties } \\
\hline & & & Room 7 & emperat & & & $650^{\circ} \mathrm{C}$ & & & & Room Ter & iperature \\
\hline & & $\begin{array}{l}0.2 \% \\
\text { Proof } \\
\text { Tress } \\
\text { MPa }\end{array}$ & $\begin{array}{l}\text { Y.S., } \\
\text { MPa }\end{array}$ & $\begin{array}{l}\text { U.T.S } \\
\text { MPa }\end{array}$ & $\% \mathrm{E}$ & \%R.A. & $\begin{array}{l}0.2 \% \\
\text { Proof } \\
\text { Tress } \\
\mathrm{MPa}\end{array}$ & Y.S. & U.T.S & $\% \mathrm{E}$ & \%R.A. & $\mathrm{J} / \mathrm{mm}^{2}$ \\
\hline 1 & 3 & 329.3 & 344.41 & 593.3 & 57.04 & 16.01 & 187.5 & 200.1 & 345.4 & 39.52 & 15.11 & 0.70 \\
\hline 2 & 3.5 & 326.7 & 344.3 & 602.7 & 38.24 & 14.47 & 135.9 & 189.4 & 347.2 & 43.28 & 14.73 & 0.68 \\
\hline 3 & $\begin{array}{l}\text { Base } \\
\text { Metal }\end{array}$ & 325.0 & 345.4 & 598.6 & 46.55 & 20.6 & 179.7 & 190.3 & 348.25 & 36.6 & 22.13 & 0.79 \\
\hline
\end{tabular}


Table 3. Creep - Rupture Properties of 316L(N) SS welded joints at different stresses and at $650^{\circ} \mathrm{C}$

\begin{tabular}{|c|c|c|c|c|c|c|c|c|c|c|}
\hline $\mathrm{Sl}$ & Power & \multicolumn{9}{|c|}{ Creep Properties, $650^{\circ} \mathrm{C}$} \\
\hline \multicolumn{11}{|c|}{ Stress, MPa } \\
\hline & & 180 & & & & 200 & & & 220 & \\
\hline & & $\begin{array}{l}\text { Rupture } \\
\text { Life, hrs }\end{array}$ & $\% \mathrm{E}$ & $\%$ RA & $\begin{array}{l}\text { Rupture } \\
\text { Life, hrs }\end{array}$ & $\% \mathrm{E}$ & $\%$ RA & $\begin{array}{l}\text { Rupture } \\
\text { Life, hrs }\end{array}$ & $\% \mathrm{E}$ & $\%$ RA \\
\hline 1 & 3 & 1328.3 & 47.08 & 22.16 & 812.8 & 57.68 & 43.7 & 173 & 57.86 & 28.65 \\
\hline 2 & 3.5 & 3048.8 & 54.18 & 22.83 & 1027.4 & 45.50 & 19.35 & 164.4 & 54.50 & 21.44 \\
\hline 3 & $\begin{array}{l}\text { Base } \\
\text { Metal }\end{array}$ & 1837 & 49.59 & 27.67 & 786 & 46.34 & 22.16 & 160 & 46.38 & 29.23 \\
\hline
\end{tabular}

\section{Conclusions}

1) $316 \mathrm{~L}(\mathrm{~N}) \mathrm{SS}$ can be satisfactorily welded using laser welding with weld metal properties at least equivalent to those of the base metal. Micro hardness test results across the welded joints are also in agreement with the tensile test results.

2) Laser welded $316 \mathrm{~L}(\mathrm{~N}) \mathrm{SS}$ weld metal has not revealed any delta- ferrite in the weld metal, when etched and observed metallographically. However, ferrite scope had shown ferrite numbers in the weld metal which are not significantly different from those of the base metal.

3) Creep failures occurred in an intergranular fashion at all the stresses studied. Cavities and wedge cracks nucleated during creep deformation. Voids linked up together during the course of the creep deformation forming micro-cracks. Micro-cracks linked up together forming full length boundary cracks.

4) Full length boundary cracks constituted the fracture forming a major crack along the grain boundaries.

5) Creep rupture times of the weld deposits are significantly higher than those of the base metal except the 3.0KW laser power and $180 \mathrm{Mpa}$ creep tested.

6) At higher stresses creep rupture samples revealed higher percentage population of wedge cracks as compared to that of at lower stress levels.

\section{Acknowledgement}

Authors wish to Acknowledge the help of Indira Gandhi Centre for Atomic Research (IGCAR) Kalpakkam for testing the $316 \mathrm{~L}(\mathrm{~N})$ material used in the present investigation. They are thankful to Dr. G. Padmanabhan, Director, International Advanced Research Centre for Powder Metallurgy and New Materials (ARCI), Balapur, Hyderabad for giving permission and allowing them to carry out the fabrication of weldments at their premises. The Authors are grateful to Shanmugarajan of ARCI for suggesting the material for carrying out the various investigations in the present work. His assistance in the fabrication of $316 \mathrm{~L}(\mathrm{~N})$ weldments is to be acknowledged to a very great extent. Dr. A. Somi Reddy wishes to acknowledge the encouragement of VITS group institutions, Bypass road, Bommakal village, Karimnager for allowing him to carry out various investigations at other places like IGCAR Kalpakkam. D. Harish kumar is grateful to a very great extent to the Management of SR Engineering College, Ananthasager, Warangal for Extending leave as and when required during the course of this investigation. D. Harish kumar and Dr. A. Somi reddy are grateful to Dr. Baldev Raj, Ex-Director IGCAR Kalpakkam for his encouragement in pursuing the research work. Both of them are also thankful to Dr. S. C. Chetal, Director, IGCAR Kalpakkam for allowing them to carry out the experiments at their premises. D.Harish kumar also wishes to acknowledge the encouragements of Sri M.Lokanath rao, Sri P. V. Rao Ex HOD of Mechanical Engineering, Dr. Gururaj, HOD of Mechanical Engineering Department KITS Warangal, Dr. Gururao, Ex-Principal, KITS Warangal, Dr. Ashok Reddy, Principal KITS, Warangal for. He is grateful to Dr. Sitarama Raju, Vice-Principal of JNTU Hyderabad for his encouragement in carrying out the research work. Dr. A. Somi reddy is grateful to Prof., K. S. S. Murthy and Dr. M. R. Shesadri of Indian institute of science, Bangalore for encouraging him in pursuing research work.

\section{References}

Arumulla, S. R. (1985). Fatigue and Creep Behavior of Aged Alloys based on Al-4\%Cu-0.3\% Mg. Thesis submitted to Monasu University, Clayton, Victoria, 3168, Melbourne, Australia. 
Baldev, Raj, \& Choudary, B. K. (2010). A Perspective on Creep and Fatigue Issues in Sodium Cooled Fast

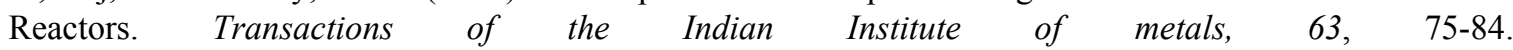
http://dx.doi.org/10.1007/s12666-010-0011-3

Chandrasekhar, N., \& Vasudevan, M. (2010). Intelligent Modeling for Optimization of A-TIG Welding Process. $\begin{array}{llll}\text { Materials and } \quad \text { Manufacturing } & \text { 1341-1350. }\end{array}$ http://dx.doi.org/10.1080/10426914.2010.529584

Do Trabalho, C. (2009). Characterization of Nd: YAG pulsed laser welded austenitic AISI 304 stainless steel. $V$. Congresso Brasileiro De Engenharia De Fabricacal $14 a 17$ de abril de Belo Horizonte - Minas /Gerais Brasil.

Ganesan, V., Mathew, M. D., Parameswaran, P., \& Bhanu Sankara Rao, K. (2010). Creep Strengthening of Low Carbon Grade Type 316LN Stainless Steel by Nitrogen. Transactions of the Indian Institute of metals, 63, 417-421. http://dx.doi.org/10.1007/s12666-010-0057-2

Ganeshan, V., Mathew, M. D., Parameshwaran, P., \& Laha, J. (2012). Effect of Nitrogen on Evolution of Dislocation Substructure in $316 \mathrm{LN}$ SS During Creep. $6^{\text {th }}$ International Conference on Creep, Fatigue and Creep-Fatigue Interaction(CF-6), 22-25,

Girish Shastry, C., Mathew, M. D., Bhanu Shankar Rao, K., Mannan, S. L., \& Pathak, S. D. (2004). Creep of 316L(N) Stainless Steel-Mechanistic and Engineering Aspects. International Symposium of Research Students on Materials Science and Engineering, Department of metallurgical and Materials Engineering. Indian Institute of Technology, Madras, 20-22.

Harish Kumar, D., \& Somi Reddy, A. (2009). A Model For the Estimation of Penetration Depth in Laser Welding Processes. International Institute of Welding, Singapore, 12.

Harish Kumar, D., \& Somi Reddy, A. (2010). An Investigation Into Influencing Factors On Welding Of 316LN Stainless Steel. National conference, Indian Institute of Welding, Vishakhapatnam Steel Plant, Vizag.

Harish Kumar, D., \& Somi Reddy, A. (2010). Laser Welding of 316LN Austenitic Stainless Steels. National Conference, KITS.

Kassner, M. E., \& Perez-Prado, M. T. (2004). Fundamentals of creep in metal and alloys, Elsevier Publications.

Kaufman, J. G. (1999). Properties of aluminum alloys: tensile, creep and fatigue data at high and low temperatures. ASM Hand book.

Kim, W. G., \& Ryu, W. S. (2007). Creep Rupture Properties of Type 316LN Stainless Steel Welded by the SAW Process. Solid State Phenomena, 119, 91-94. http://dx.doi.org/10.4028/www.scientific.net/SSP.119.91

Mathew, M. D., Laha, K., \& Sandhya, R. (2012), Creep And Cycle Fatigue Behaviour of Fast Reactor Structural Materials. $6^{\text {th }}$ International Conference on Creep, Fatigue and Creep-Fatigue Interaction (CF-6), 22-25.

Mishra, P., Borgstedt, H. U., Mathew, M. D., Mannan, S. L., \& Rodriguez, P. (1997). A Comparative Study of Creep Rupture Behaviour of Modified 316L(N) Base Metal and 316L(N) /16-8-2 Weldment in Air and Liquid Sodium Environments. Int. J. Ves. \& Piping, 72, 111-118. http://dx.doi.org/10.1016/S0308-0161(97)00016-1

Reddy, A. S., Mannan, S. L., Seetharaman, V., Rodriguez, P. (1980). Effect of the Number of Passes on the Structure and Properties of a Type AISI 316 Stainless Steel Weld Metal. National Welding Seminar, Singapore.

Sakthivel, T., Vasudevan, M., Laha, K., Parameswaran, P., Chandravathi, K. S., Mathew, M. D., \& Bhaduri, A. K. (2011). Comparison of creep rupture behavior of type $316 \mathrm{~L}(\mathrm{~N})$ austenitic stainless steel joints welded by TIG and activated TIG welding processes. Materials science and Engineering, 528, 6971-6980. http://dx.doi.org/10.1016/j.msea.2011.05.052

Sakthivel, T., Vasudevan, M., Laha, K., Parameswaran, P., Chandravathi, K. S., Mathew, M. D., \& Bhaduri, A. K. (2012). Effect of joining process on the accumulation of creep deformation and cavitation across the weld joint of $316 \mathrm{~L}(\mathrm{~N})$ Steel. $6^{\text {th }}$ Intenational conference on Creep, Fatigue and Creep-Fatigue Interaction (CF-6), 22-25.

Tjong, S. C., Zhu, S. M., Ho, N. J., \& Ku, J. S. (1995). Micro structural Characteristics and Creep Rupture Behavior of Electron Beam and Laser Welded AISI 316L Stainless Steel. Journal of Nuclear Materials, 227, 24-31. http://dx.doi.org/10.1016/0022-3115(95)00142-5 
Vasantharaja, P., Maduarimuthu, V., Vasudevan, M., \& Palanichamy, P. (2012). Assessment of Residual Stresses and Distortion in Stainless Steel Weld Joints. Materials and Manufacturing Processes. http://dx.doi.org/10.1080/10426910701323342

Vasudevan, M. (2009). Soft Computing Techniques in Stainless Steel Welding. Materials and Manufacturing Processes, 24, 2, 209-218. http://dx.doi.org/10.1080/1042691070132334

Vasudevan, M., Bhaduri, A. K., Baldev Raj, \& Prasad Rao, K. (2007). Genetic-Algorithm-Based Computational Models for Optimizing the Process Parameters of A-TIG Welding to Achieve Target Bead Geometry in Type $304 \mathrm{~L}(\mathrm{~N})$ and $316 \mathrm{~L}(\mathrm{~N})$ Stainless Steels. Materials and Manufacturing Processes, 22, 641-649. http://dx.doi.org/10.1080/10426910701323342

Wouter, S. M., Powell, J., \& Kalpan, A. (2006). The Influence of Joint gap on the Strength of hybrid NdYittrium- Aluminium- Garnet laser metal inert gas welds. Journal of Laser Applications, 18(3), 181-184. http://dx.doi.org/10.2351/1.2227009 